\title{
Evaluating trauma care capabilities in Mexico with the World Health Organization's Guidelines for Essential Trauma Care publication
}

\author{
Carlos Arreola-Risa, ${ }^{1}$ Charles Mock, ${ }^{2}$ Felipe Vega Rivera, ${ }^{3}$ \\ Eduardo Romero Hicks, ${ }^{4}$ Felipe Guzmán Solana, ${ }^{5}$ Giovanni Porras Ramírez, ${ }^{6}$ \\ Gilberto Montiel Amoroso, ${ }^{7}$ and Melanie de Boer $^{8}$
}

ABSTRACT Objective. To identify affordable, sustainable methods to strengthen trauma care capabilities in Mexico, using the standards in the Guidelines for Essential Trauma Care, a publication that was developed by the World Health Organization and the International Society of Surgery to provide recommendations on elements of trauma care that should be in place in the various levels of health facilities in all countries.

Methods. The Guidelines publication was used as a basis for needs assessments conducted in 2003 and 2004 in three Mexican states. The states were selected to represent the range of geographic and economic conditions in the country: Oaxaca (south, lower economic status), Puebla (center, middle economic status), and Nuevo León (north, higher economic status). The sixteen facilities that were assessed included rural clinics, small hospitals, and large hospitals. Site visits incorporated direct inspection of physical resources as well as interviews with key administrative and clinical staff.

Results. Human and physical resources for trauma care were adequate in the hospitals, especially the larger ones. The survey did identify some deficiencies, such as shortages of stiff suction tips, pulse oximetry equipment, and some trauma-related medications. All of the clinics had difficulties with basic supplies for resuscitation, even though some received substantial numbers of trauma patients. In all levels of facilities there was room for improvement in administrative functions to assure quality trauma care, including trauma registries, traumarelated quality improvement programs, and uniform in-service training.

Conclusions. This study identified several low-cost ways to strengthen trauma care in Mexico. The study also highlighted the usefulness of the recommended norms in the Guidelines for Essential Trauma Care publication in providing a standardized template by which to assess trauma care capabilities in nations worldwide.

Key words Emergency medical services, quality of health care, guidelines, Mexico.

Secretaría de Salud, Sistema Estatal de Atención de Emergencias Médicas, Monterrey, Nuevo León, México.

2 University of Washington, Harborview Injury Prevention and Research Center, Seattle, Washington, United States of America. Send correspondence to: Charles Mock, Harborview Injury Prevention and Research Center, Box 359960, Harborview Medical
Center, 325 Ninth Avenue, Seattle, WA, United States of America; telephone: 206-744-9430; fax: 206-744-9962; e-mail: cmock@u.washington.edu

3 Cruz Roja, Hospital Central, Departamento de Emergencias/División Trauma, México, D.F., México.

4 Secretaría de Salud, Sistema de Urgencias del Estado, Guanajuato, Guanajuato, México.
5 Hospital Civil, Oaxaca de Juárez, Oaxaca, México.

6 Secretaría de Salud, Puebla, Puebla, México.

7 Secretaría de Salud, Monterrey, Nuevo León, México.

8 Pan American Health Organization, México, D.F., México. 
Trauma has become a leading health problem in low- and middle-income countries (LMICs). However, strategies to deal with it have not been well worked out, whether for prevention or treatment. Experience from highincome countries has demonstrated that improvements in survival can accrue with better organization and planning for trauma care services. Well-organized trauma systems have decreased mortality among all treated trauma patients by $15 \%-20 \%$ and decreased medically preventable deaths by $50 \%$ (1-5). However, such evidence comes primarily from high-income countries.

Until recently, no set of standards existed to guide trauma system development in LMICs. Due to economic realities it is not reasonable to utilize recommendations from high-income countries verbatim. In an effort to provide recommendations tailored to the needs of LMICs, the Essential Trauma Care Project was established. This project has involved a collaborative working group formed by the World Health Organization (WHO) and the International Society of Surgery. The working group has received input from trauma care clinicians from at least one country on every continent. Over the past three years the working group has worked to develop recommendations on ways to strengthen the planning and organization of trauma care services around the world (6-8).

The recommendations of the working group have been published by the WHO in the Guidelines for Essential Trauma Care (9). The publication sets forth 14 core essential trauma care services that can reasonably be provided to every injured person in every country. These include basic items of care such as opening obstructed airways, stopping hemorrhage, and preventing disability from extremity injuries. To assure these services, 260 individual items of skills and staffing (human resources) and equipment and supplies (physical resources) were deemed to be either essential or desirable in the various levels of health facilities around the world, from small clinics to tertiary care facilities. These Guidelines stan- dards are intended to serve as a flexible template to assist ministries of health and individual facilities in planning to optimize their trauma services, so as to improve both survival and functional outcome.

In our study in Mexico we sought to identify priorities for affordable and sustainable methods to strengthen trauma care capabilities in the country. To ascertain these priorities, we used the Guidelines for Essential Trauma Care as a standard by which to evaluate these capabilities in the range of facilities providing trauma care in the country. The Guidelines standards have been used in smaller pilot assessments in several other countries, including Ghana, India, and Vietnam. However, to our knowledge, this is the first time that the criteria in the Guidelines publication have been used to generate as broad a nationwide picture as we have done in our study of Mexico.

\section{METHODS}

\section{Site selection}

Three of Mexico's 31 states were purposively selected to represent the country's geographic and socioeconomic spectrum: Oaxaca (south, lower economic tercile), Puebla (center, middle tercile), and Nuevo León (north, upper tercile) (10). In all three states the state government's Secretariat of Health (Secretaría de Salud), prominent local trauma care clinicians, and representatives of the Mexican Association of Medicine and Trauma Surgery (Asociación Mexicana de Medicina y Cirugía de Trauma) planned the project together. The facilities selected for review in each state included two or three large hospitals (100-400 beds) that were in the state capital and were the busiest hospitals for trauma care in the state. In some of the state capitals there were other large hospitals, but they were not the main hospitals for trauma and they catered to other health problems. Although they might occasionally receive some trauma patients, these other large hospitals were not evaluated in this study.
Also chosen were one or two small general hospitals (30-50 beds) located in small towns and rural areas outside the state capitals. Each state tended to have 10-20 such general hospitals. Also chosen were one or two representative rural clinics that had high trauma volumes. Each state had 200 400 such clinics. All the facilities evaluated were government-operated or government-affiliated. Such facilities were chosen since they provide the vast majority of trauma care in each state. No private facilities were assessed for this study.

\section{Criteria for evaluation}

Two forms were created for this study. The first was a two-page questionnaire that assessed overall characteristics such as composition and availability of the trauma care staff. The questionnaire also addressed the percent of trauma care providers who were credentialed in continuing education (in-service) courses such as Advanced Trauma Life Support (ATLS) (11) or Trauma Nursing Core Course (TNCC) (12). Information on trauma registries and quality improvement programs was obtained. Finally, staffs were given open-ended questions asking them to describe any problems they faced in providing trauma care.

The second form was an 11-page checklist using 200 of the 260 individual items of human and physical resources contained in the Guidelines for Essential Trauma Care. Essential items are those that are deemed by consensus to be the most cost-effective and that could realistically be assured to almost any patient at a given level of the health care system in any country. Desirable items are those that add value but are not as cost-effective and are more applicable to middle-income environments. As Mexico is a middleincome country, both essential and desirable items were included in the checklist. The 60 of the 260 items that were not included in the checklist used for this study were primarily individual trauma-related medications outlined in the Guidelines. In our checklist 
the general topic of availability of trauma-related medications was included as one item.

\section{Site visit process}

The questionnaire and checklist were both used to interview key staff at each facility. These included hospital or clinic directors; chiefs of surgery, orthopedics, and other relevant specialties; emergency department (ED) chiefs; nursing directors; and clinicians (doctors and nurses) on duty in the ED, intensive care unit (ICU), and hospital wards. Direct inspections of facilities and equipment in the ED and ICUs were carried out. At least three of the authors were present for each site visit. Visits lasted between 3 hours (small clinics) and 10 hours (large hospitals). The visits were conducted in 2003 and 2004.

Each of the 200 items on the checklist was assessed and then put into one of five categories: not applicable at that level of the health care system; absent, given a rating of 0 ; inadequate (fewer than half of those who need this service or item receive it when needed), a rating of 1 ; partly adequate (most but not all of those who need this service or item receive it when needed), a rating of 2; and adequate (virtually all of those who need this service or item receive it when needed), a rating of 3 .

Items were assessed based on the criteria for the corresponding level of the health care system, with increasing requirements for the higher levels. Items were assessed based on their timely availability for all who need them, not their mere physical presence. For example, a diagnostic test that frequently could not be performed because of a lack of reagents or because the test equipment was awaiting repairs would be rated as a 1 or 2, even if the equipment for the test was present. Services that required payment in advance and that were not routinely provided to all who needed them without regard of ability to pay would be rated as 1 or 2 . As indicated in the Guidelines for Essential Trauma Care, cost-recovery schemes may be applied after care is rendered, but they should not interfere with the provision of initial, essential items of emergency care.

In the Results text section and tables, the results of these ratings are provided for each category of health facility in each state. If more than one health facility in a category was assessed in a particular state, a single rating was given that encompassed all the facilities of that level that were assessed in that state. Such "average" ratings took into account whether the essential and desirable services were being received by none (rating 0), fewer than half (rating 1), more than half but not all (rating 2), or virtually all trauma patients (rating 3 ) requiring those services at those facilities combined (i.e., all facilities of that level assessed in that state). For example, if there were two facilities and one of them rated a 3 but the other facility provided the particular service to only $60 \%$ of the trauma victims who needed it, then the "average" rating for the two facilities together would be 2 (partly adequate).

For the purposes of this paper several highly important individual items from among the 200 were selected for analysis. In addition, summaries of the reports of the two-page baseline questionnaire are reported. The Guidelines publication utilizes four categories: clinics, small generalist-staffed hospitals, specialist-staffed hospitals, and tertiary care facilities. The "small generaliststaffed hospital" is rare in Mexico. Thus, for the purpose of this study, we utilized three levels: clinic, small hospital (all having some degree of specialist staffing), and large hospital.

The names of respondents were not recorded. The study was approved by the Secretariat of Health of each of the three states.

\section{RESULTS}

\section{Sites}

Five clinics, four small hospitals, and seven large hospitals were surveyed (Table 1). The large hospitals had 1000 to 9000 trauma admissions annually. The small hospitals had 150 to 300 trauma admissions plus an equal number of transfers to large hospitals annually. All hospitals had much greater numbers of trauma outpatient visits. The clinics reported 4 to 10 trauma outpatient visits daily, with 10 to 15 trauma transfers per month.

\section{Human resources}

General doctors, whether fully qualified or in social service, are the principal doctors staffing rural clinics. (Social service in Mexico is a period of public service that junior doctors are required to provide, usually during the year immediately after graduation from medical school. The doctors are typically posted to rural areas or other underserved areas for that year.) There is usually one fully qualified or social service doctor per clinic. Thus, clinics tend to have less than full-time coverage, during periods when the one doctor is away (Table 1). Nurse coverage was less problematic at these facilities. At all hospitals, ED staffing with general or emergency physicians was adequate. However, all hospitals reported some problems with sufficient nursing personnel to staff the ED. Most hospitals were well supplied with specialtytrained doctors, except for slight problems in some southern (Oaxaca) hospitals.

In-service trauma training for doctors, in the form of the ATLS course, was minimal at most rural clinics and small hospitals. Coverage was better, but still incomplete and variable, at large hospitals, with credentialing rates ranging from $15 \%$ to $100 \%$. Facilities with complete or near-complete ATLS credentialing reported similar methods for assuring this, in that they required and subsidized the course for general surgeons and ED providers.

Most large hospitals did have some locally developed trauma-related inservice training for ED nurses. However, externally validated training, such as TNCC, was nearly absent.

Staffing for rehabilitative services varied widely (Table 1). In general, 
TABLE 1. Ratings for training and for staffing levels for key trauma care personnel at facilities in three regions of Mexico, 2003-2004 ${ }^{a, b}$

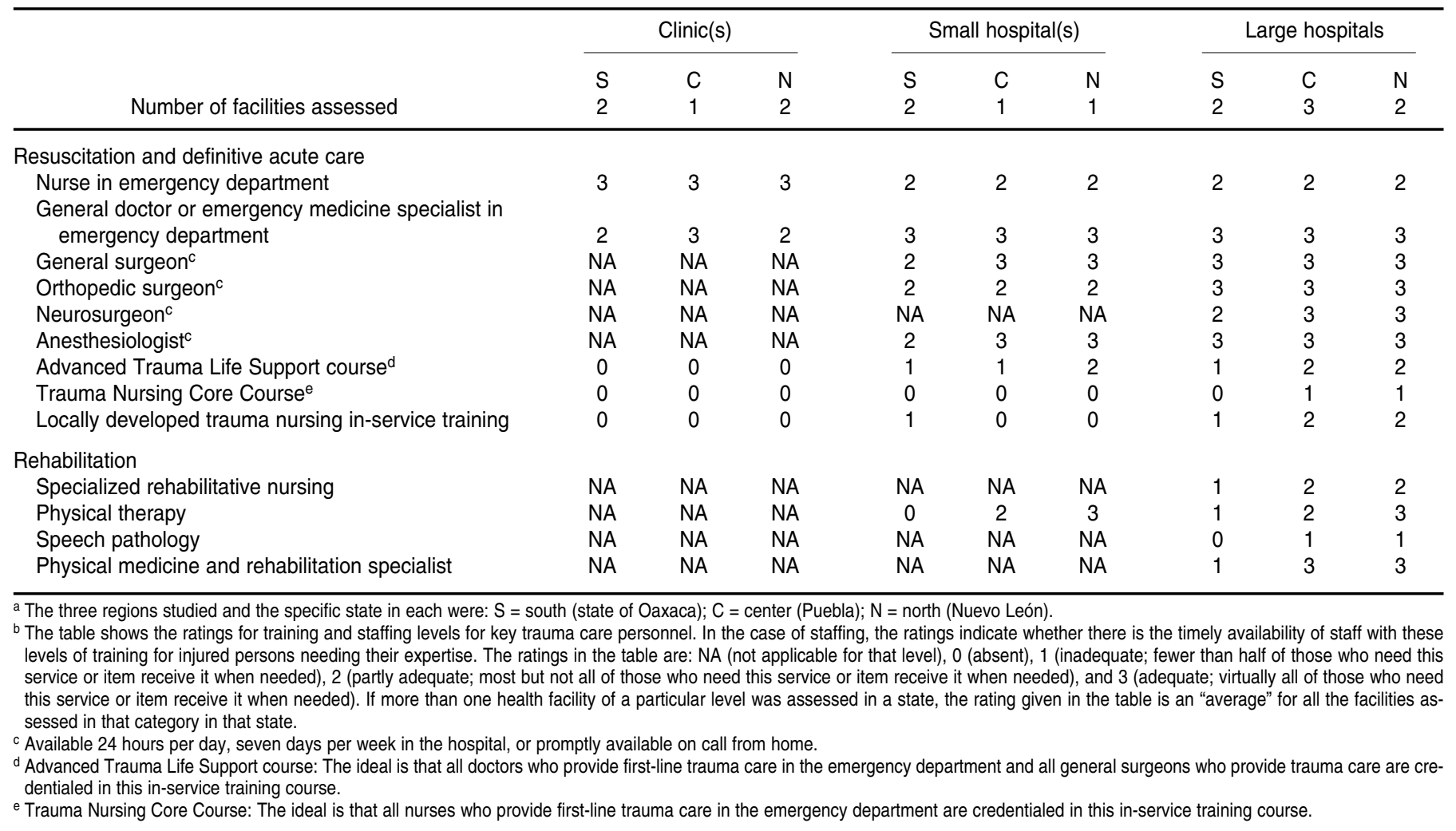

human resources for rehabilitation were not as well developed as for acute care.

\section{Physical resources}

Resources for acute resuscitation (Table 2) were extremely limited at clinics. Especially problematic was oxygen. This was identified as a major problem at all clinics. Problems ranged from no supply to frequent, prolonged shortages when the one tank per clinic was away for refilling. Small hospitals identified lack of pulse oximetry as a major issue. Large hospitals were mostly fairly well supplied for acute resuscitation. Most did report occasional problems with blood supply, such as a lack of adequate numbers of units of commonly used blood types. There were also occasional problems with a lack of chest tubes and with breakdowns or a lack of reagents inter- fering with full-time availability of laboratory examinations. All facilities identified lack of immediate availability of stiff suction tips in the ED, although they may have been present elsewhere in the hospital.

The issue of resources for management of specific injuries largely did not apply to clinics (Table 3). Small hospitals were fairly well supplied except for two things: (1) diagnostic capabilities for abdominal injuries and (2) some operative capabilities, primarily relating to shortages of operating room equipment. Large hospitals reported some shortcomings, such as difficulties with optimizing head injury management. All large hospitals had computerized axial tomography, but some reported prolonged periods of lack of service while awaiting repairs.

No facility had capabilities for autotransfusion from chest tubes. Prostheses for amputees were absent in al- most all locations. Almost every institution reported difficulties with trauma-related medications, especially antibiotics and analgesics. There were frequent shortages, with relatives needing to buy medications from private pharmacies.

Resource availability paralleled economic status, with better availability in the more prosperous center (Puebla) and north (Nuevo León).

\section{Security for health care personnel}

Protection from potential body-fluidborne diseases was partially adequate (Table 4). All staff had received training in universal precautions. There were sufficient gloves at most facilities, but occasional shortages at some other facilities. Goggles were intermittently available and not well utilized. Sharps and biological waste disposal was very good, with a few exceptions. Antiretro- 
TABLE 2. Ratings for physical resources (equipment and supplies) for acute resuscitation of trauma victims at facilities in three regions of Mexico, 2003-2004,

\begin{tabular}{|c|c|c|c|c|c|c|c|c|c|}
\hline \multirow[b]{2}{*}{ Number of facilities assessed } & \multicolumn{3}{|c|}{ Clinic(s) } & \multicolumn{3}{|c|}{ Small hospital(s) } & \multicolumn{3}{|c|}{ Large hospitals } \\
\hline & 2 & 1 & 2 & 2 & 1 & 1 & 2 & 3 & 2 \\
\hline \multicolumn{10}{|l|}{ Airway } \\
\hline Oral and nasal airway devices & 0 & 0 & 1 & 3 & 3 & 3 & 3 & 3 & 3 \\
\hline Suction device & 0 & 0 & 0 & 3 & 3 & 3 & 3 & 3 & 3 \\
\hline Yankauer or other stiff suction tip & 0 & 0 & 0 & 2 & 0 & 2 & 2 & 2 & 2 \\
\hline Stethoscope & 3 & 2 & 3 & 3 & 3 & 3 & 3 & 3 & 3 \\
\hline Oxygen supply & 0 & 1 & 1 & 3 & 3 & 3 & 3 & 3 & 3 \\
\hline Chest tubes & NA & NA & NA & 2 & 3 & 3 & 3 & 2 & 3 \\
\hline Pulse oximetry & NA & NA & NA & 0 & 2 & 2 & 2 & 3 & 2 \\
\hline Arterial blood gas determinations & NA & NA & NA & 0 & 0 & 0 & 2 & 3 & 3 \\
\hline Bag-valve-mask & 2 & 3 & 2 & 3 & 3 & 3 & 3 & 3 & 3 \\
\hline Blood transfusion capability & NA & NA & NA & 1 & 2 & 2 & 2 & 2 & 2 \\
\hline Urinary catheter & 2 & 2 & 2 & 2 & 3 & 3 & 2 & 3 & 3 \\
\hline Electronic cardiac monitoring & NA & NA & NA & 2 & 1 & 2 & 1 & 2 & 2 \\
\hline Hemoglobin determination & 0 & 0 & 1 & 3 & 3 & 3 & 3 & 3 & 3 \\
\hline Electrolyte determinations & NA & NA & NA & 1 & 3 & 3 & 2 & 3 & 3 \\
\hline Lactic acid determination & NA & NA & NA & 0 & 0 & 0 & 0 & 1 & 0 \\
\hline Fluid warmer & NA & NA & NA & 0 & 0 & 2 & 0 & 2 & 2 \\
\hline
\end{tabular}

viral post-exposure prophylaxis was only intermittently available.

\section{Administrative functions}

Administrative functions specific to trauma care were notably weak (Table 5). Although many facilities had good medical record systems and could identify the number of trauma admissions of various types, none had a formal trauma registry with severity adjustment by the Injury Severity Score or another scoring system. Most hospitals integrated trauma cases into broader quality improvement programs. However, none of the larger hospitals had a specific trauma-related quality improvement program identifying medically preventable deaths. Rural clinics did not include trauma cases in their quality improvement activities. Use of trauma teams with pre- assigned roles in acute resuscitations was low in all locations.

\section{DISCUSSION}

The purpose of the study was to identify priorities for affordable, sustainable methods to strengthen trauma care capabilities in Mexico. Before drawing conclusions, the limitations of the study must be addressed. First, the larger hospitals studied were the main trauma care hospitals in each state. However, there were many smaller hospitals and a great many rural clinics to choose from. Small hospitals and clinics with high trauma volumes that were fairly representative were chosen. Nonetheless, the small numbers of these facilities surveyed diminishes the ability to generalize and to evaluate differences among the three states.
Second, although physical inspection of equipment and supplies was objective, information on the process of care depended mostly on key informant interviews. Ratings (0-3) were often based on subjective opinions. One might expect these ratings to vary with whether the chief or administrator was interviewed, compared with doctors or nurses who were directly providing care. At each facility the authors attempted to overcome this potential problem by interviewing a range of persons, including chiefs, administrators, and doctors and nurses who were directly providing care.

Third, there was no way to verify the competency or skills under the human resources sections of the checklist. We utilized, as a proxy, availability of certain specialties and the completeness of in-service training.

Fourth, improvements in human and physical resources do not neces- 
TABLE 3. Ratings for physical resources for management of specific injuries at facilities in three regions of Mexico, 2003-2004a, b, c

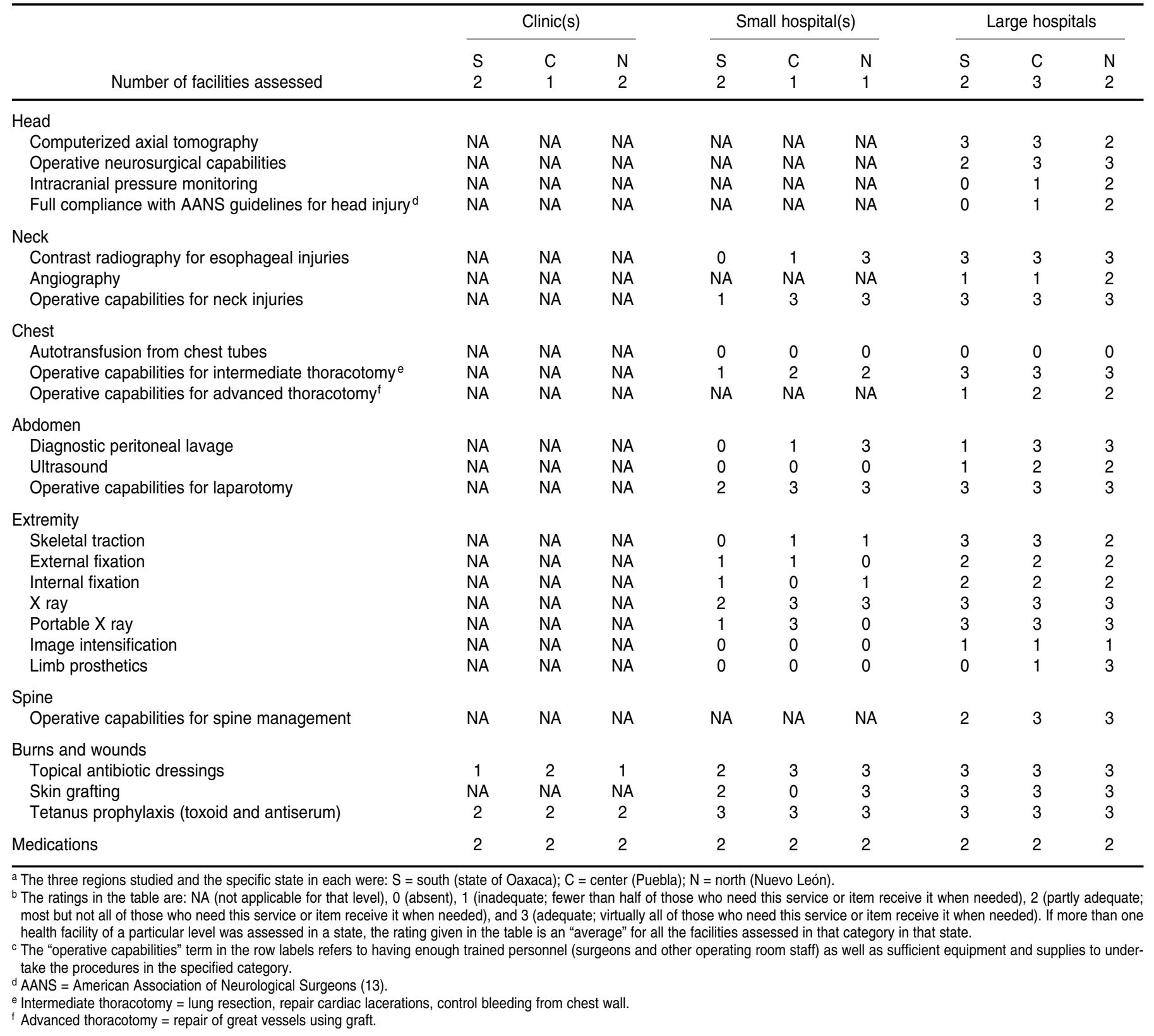

sarily lead to improved outcome. However, efforts to improve such resources constitute improvements in "structure" that are in turn an integral part of longer-term efforts to improve "process" and "outcome."

Despite these limitations the study provides a more comprehensive assessment of trauma care capabilities than has previously been reported for Mexico or other LMICs. Moreover, by including the main trauma hospitals in the state capitals, we evaluated facilities providing care to over half of all seriously injured patients in each state.

The study showed that, except for smaller southern (Oaxaca) hospitals, hospitals at all levels were well supplied with general doctors, surgical specialists, and anesthesiologists. Rural clinics were primarily staffed by junior doctors, none of whom had any particular trauma training. Adequate ED nursing staffing was identified as a problem in all the hospitals.

Concerning in-service training, the ATLS program has been established in Mexico for over 10 years and has trained thousands of doctors (11, 14, 15). ATLS certification for all doctors with significant trauma care responsibility is regarded as the ideal for all hospitals in Mexico. Nonetheless, almost all of the main hospitals providing trauma care in the state capitals had 
TABLE 4. Ratings for supplies and services for the security of health care personnel at facilities in three regions of Mexico, 2003-2004 ${ }^{a, b}$

\begin{tabular}{|c|c|c|c|c|c|c|c|c|c|}
\hline \multirow[b]{3}{*}{ Number of facilities assessed } & \multicolumn{3}{|c|}{ Clinic(s) } & \multicolumn{3}{|c|}{ Small hospital(s) } & \multicolumn{3}{|c|}{ Large hospitals } \\
\hline & $S$ & C & $\mathrm{N}$ & S & C & $\mathrm{N}$ & S & C & $\mathrm{N}$ \\
\hline & 2 & 1 & 2 & 2 & 1 & 1 & 2 & 3 & 2 \\
\hline Training in universal precautions & 3 & 3 & 3 & 3 & 3 & 3 & 3 & 3 & 3 \\
\hline Gloves & 3 & 3 & 3 & 2 & 3 & 3 & 2 & 3 & 3 \\
\hline Goggles & 0 & 0 & 0 & 0 & 1 & 3 & 1 & 2 & 3 \\
\hline Sharps and biological waste disposal & 3 & 2 & 3 & 3 & 3 & 3 & 3 & 3 & 2 \\
\hline Antiretroviral post-exposure prophylaxis & 0 & 0 & 3 & 1 & 1 & 1 & 2 & 3 & 2 \\
\hline
\end{tabular}

a The three regions studied and the specific state in each were: $\mathrm{S}=$ south (state of Oaxaca); $\mathrm{C}=$ center (Puebla); $\mathrm{N}=$ north (Nuevo León).

${ }^{b}$ The table shows ratings for supplies and services for the security of health care personnel, primarily in terms of protecting personnel from body fluid exposure and the transmission of related bloodborne diseases. The ratings for gloves and goggles take into account both availability and utilization. The ratings in the table are: NA (not applicable for that level), 0 (absent), 1 (inadequate; fewer than half of those who need this service or item receive it when needed), 2 (partly adequate; most but not all of those who need this service or item receive it when needed), and 3 (adequate; virtually all of those who need this service or item receive it when needed). If more than one health facility of a particular level was assessed in a state, the rating given in the table is an "average" for all the facilities assessed in that category in that state.

TABLE 5. Ratings for administrative and organizational functions at facilities in three regions of Mexico, 2003-2004a, b

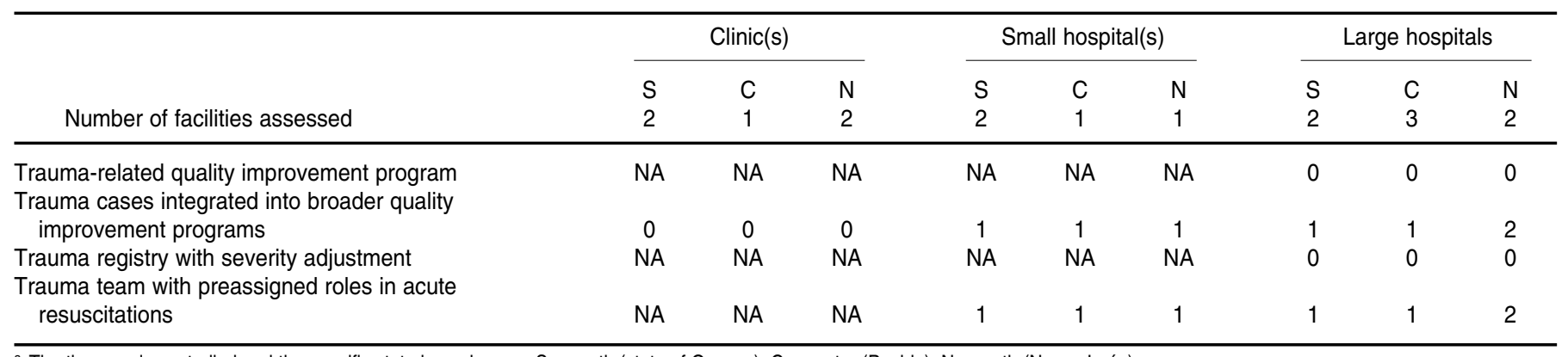

a The three regions studied and the specific state in each were: $\mathrm{S}=$ south (state of Oaxaca); $\mathrm{C}=$ center (Puebla); $\mathrm{N}=$ north (Nuevo León).

b The table shows ratings for administrative and organizational functions that can be used to assure the quality of trauma care. The ratings in the table are: NA (not applicable for that level), 0 (absent), 1 (inadequate; fewer than half of those who need this service or item receive it when needed), 2 (partly adequate; most but not all of those who need this service or item receive it when needed), and 3 (adequate; virtually all of those who need this service or item receive it when needed). If more than one health facility of a particular level was assessed in a state, the rating given in the table is an "average" for all the facilities assessed in that category in that state.

incomplete ATLS coverage. At most of these hospitals fewer than $50 \%$ of the doctors with significant trauma care responsibilities were ATLS-certified; at some, only $15 \%-20 \%$ were certified. Certification was especially low in small hospitals.

The study identified several items of equipment that could be better supplied, especially at small hospitals and rural clinics. The availability of oxygen was especially problematic for clinics. Most facilities indicated some limitations with blood transfusion capability and with adequate supplies of traumarelated medications. However, compared to findings in similar, smaller needs assessments done in low-income countries $(16,17)$, the facilities in Mexico were nearly adequately supplied with the basic, essential items of trauma care.

There are several higher-cost items that the Guidelines for Essential Trauma Care publication lists as "desirable" rather than "essential" for specialist and tertiary care facilities. These items, such as image intensification and angiography, were largely absent or deficient at the facilities studied in Mexico. At the large hospitals, many of the staff members indicated they would like to have these items. Likewise, at small hospitals several higher-cost, but possibly appropriate, items were scarce, including pulse oximetry and electronic cardiac monitoring. The need for such higher-cost items could be better justified if it could be documented that the outcome for a substantial number of patients could be improved with these modalities. This would entail having an adequate source of information (e.g., trauma registry) and a process to monitor such outcomes through quality improvement programs.

Therefore, a major finding of this study is the low level of development of such organizational and administrative mechanisms. Many hospitals did have reasonable health information systems that allowed them to summarize the number of admissions by major diagnosis and mechanism of in- 
jury. However, no hospital had a formal trauma registry using risk adjustment $(18,19)$.

In terms of quality improvement, all the hospitals indicated that they had the committees mandated by the national Secretariat of Health for facilities of their size. These included committees that monitored mortality in general, infections, and maternal mortality. Obviously, hospitals with high trauma volumes would have trauma patients show up in reports of these committees. Likewise, it is important to note that such committees, especially a wellfunctioning mortality committee, are the foundation upon which quality improvement programs are built. Nonetheless, no hospital had a program specifically for trauma-related quality improvement. No hospital tracked preventable deaths using autopsy findings or risk adjustment. Most hospitals indicated that they did not have access to autopsy findings, and the few hospitals that did said that these findings were utilized very infrequently. This is despite the fact that in all three states the majority of all trauma victims undergo an autopsy by the state forensic department. The clinics indicated they had programs that monitored diabetes management, prenatal care, respiratory infections, and a few other health problems, but not trauma.

Another organizational issue is the use of a designated trauma team with preassigned roles and positions at the patient's bedside during resuscitations. Such trauma team organization was minimal at most hospitals.

Major recommendations from this study include the need to strengthen organization and planning for trauma care services through uniform in-service training, trauma registries, traumarelated quality improvement programs, and trauma team organization.

The importance of uniform inservice training bears emphasis. In Trinidad and Tobago, another middleincome country, mortality decreased from $67 \%$ to $34 \%$ among the most severely injured patients at that country's major hospital after institution of uniform ATLS training in the facility
(20). As noted above, although the ATLS program has been present in Mexico for many years, ATLS training levels were low in the facilities in our study, particularly in the rural areas. This emphasizes the need for a more unified approach to ensuring that more staff members do receive ATLS and other in-service training. Of note, hospitals that required and subsidized ATLS for their staff had the highest levels of ATLS training. This is a model that might be considered for nationwide implementation.

A variety of standardized means for quality improvement for trauma care have been utilized, primarily in highincome countries (19). One method involves panel reviews of preventable deaths, to look at autopsy findings (if available) as well as documentation of potential deficiencies in clinical care. Such reviews build on the mortality reviews conducted routinely at most hospitals worldwide, including those in LMICs.

A second approach is severity (or risk) adjustment, using such tools as the Injury Severity Score (ISS) or the ISS combined with the Trauma Score (TRISS). The ISS is a score based on the anatomic nature of the injuries. TRISS combines this anatomic data with physiologic data in the form of the Revised Trauma Score, which is based on the Glasgow Coma Scale, systolic blood pressure, and respiratory rate. Such scores can be used to identify injured persons who die from fairly minor injuries, from which one would expect them to survive. Such cases would be priorities for quality improvement review. Such scores can also be used to look at overall hospital performance, by monitoring the percent of patients who die with low injury severity.

Audit filters are a third approach. They include monitoring the process of care for specific, highly critical procedures, such as patients with abdominal injuries and hypotension who do not undergo laparotomy within one hour of arrival at the hospital, or patients with epidural or subdural hematomas who receive craniotomy more than four hours after arrival at the hospital.
All of the above methods identify potentially preventable deaths and problems with care. A key part of the quality improvement process is to then formulate a plan to correct the problems, take the corrective actions, and document that the problems have been remedied. The problems addressed can be an individual practitioner's behavior, but more commonly they are systemwide problems.

Such formal quality improvement programs have only rarely been applied in LMICs. One excellent example of a trauma-related quality improvement program is from the province of Khon Kaen, Thailand (21). At the major hospital there a trauma registry indicated a high rate of medically preventable deaths. A trauma audit committee reviewed these deaths and identified several easily solved problems. The corrective actions that were taken included improved recordkeeping, improved communication by radio within the hospital, stationing fully trained general surgeons in the ED during peak periods, and improved trauma orientation for junior doctors. Through the trauma registry, it was demonstrated that the process of care did improve, with an accompanying decline in the mortality rate among all admitted trauma patients, from $6.1 \%$ to $4.4 \%$. Such programs should be eminently transferable to other LMICs. While such programs are not a guarantee of improvement, the above example does show that they can be useful in lowering mortality. Moreover, it should be emphasized that many high-income countries need to strengthen their own performance with health information systems for trauma and with related quality improvement programs.

A final administrative function to consider is organization of the trauma team that undertakes initial resuscitation of critically injured patients. Preassigned roles for team members and protocols to assure rapid assembly and efficient team functioning have led to improved care in developed countries and some LMICs (9, 22, 23). For example, a Turkish hospital estab- 
lished organized trauma teams to upgrade previously haphazard care. There were improvements in airway management and shock resuscitation, and mortality among the most severely injured declined from $33 \%$ to $23 \%$ (24). Wider implementation of the trauma team concept in Mexico has been recommended. ${ }^{9}$

9 Arreola-Risa C, Trevino R, Piña S, Castillo I, Hernández $\mathrm{M}$, Mock $\mathrm{C}$. Atención de pacientes politraumizados en la nueva unidad de emergencias: una nueva era [abstract]. Cir Gen. 2000;22(4 (Suplemento 1)):10.

\section{CONCLUSION}

Although human and physical resources for trauma care are fairly well supplied in Mexico, this study identified several important deficiencies that could be corrected at low cost. These shortcomings were more frequent in smaller rural hospitals and clinics, many of which do treat substantial numbers of injured persons. Of special note, the study identified a set of administrative and organizational functions that could and should be improved at all levels of care. These functions include trauma registries, trauma-related quality improvement programs, trauma team organization, and more uniform use of in-service training. This study also highlights the usefulness of the Guidelines for Essential Trauma Care in providing a standardized template to assess trauma care capabilities and to identify needed low-cost improvements in countries around the world.

Acknowledgements. We thank all the persons who took part in the study for the time, helpfulness, and insights that they contributed.

\section{REFERENCES}

1. Nathens A, Jurkovich G, Rivara F, Maier R. Effectiveness of state trauma systems in reducing injury-related mortality: a national evaluation. J Trauma. 2000;48:25-30.

2. Nathens A, Jurkovich G, Cummings P, Rivara $F$, Maier R. The effect of organized systems of trauma care on motor vehicle crash mortality. JAMA. 2000;283:1990-4.

3. Mann N, Mullins R, MacKenzie E, Jurkovich $\mathrm{G}$, Mock C. A systematic review of published evidence regarding trauma system effectiveness. J Trauma. 1999;47:S25-33.

4. Brennan PW, Everest ER, Griggs WM, Slater A, Carter L, Lee C, et al. Risk of death among cases attending South Australian major trauma services after severe trauma: 4 years of operation of a state trauma system. J Trauma. 2002;53:333-9.

5. Simons R, Eliopoulos V, Laflamme D, Brown DR. Impact on process of trauma care delivery 1 year after the introduction of a trauma program in a provincial trauma center. J Trauma. 1999;46:811-5.

6. Mock C, Joshipura M, Goosen J. Global strengthening of care of the injured [editorial]. Bull World Health Organ. 2004;82(4):241.

7. Joshipura M, Mock C, Goosen J, Peden M. Essential trauma care: strengthening trauma systems round the world. Injury. 2004;35: 841-5.

8. Mock CN, Arreola-Rissa C, Vega F, Romero Hicks E, de Boer M, Lormand JD. Fortaleciendo la atención del trauma en México y a nivel mundial: Proyecto Atención Esencial en Trauma. Trauma: Urgencia Med Hoy. 2004; 7:5-14.
9. Mock C, Lormand JD, Goosen J, Joshipura M, Peden M. Guidelines for essential trauma care. Geneva: World Health Organization; 2004.

10. México, Instituto Nacional de Estadística, Geografía e Informática. Regiones socioeconómicas de México [Web page]. Available from: http://www.inegi.gob.mx/niveles/jsp/index. jsp. Accessed 21 January 2006.

11. American College of Surgeons Committee on Trauma. Advanced Trauma Life Support for Doctors: student course manual. Chicago: American College of Surgeons; 2004.

12. Emergency Nurses Association. Trauma Nursing Core Course [Web site]. Available from: http://www.ena.org. Accessed 11 August 2005.

13. Bullock R, Chesnut R, Clifton G, Ghajar J, Marion D, Narayan R, et al. Guidelines for the management of severe traumatic brain injury. J Neurotrauma. 2000;17:451-553.

14. Krantz BE. The international ATLS program. Trauma Q. 1999;14:323-8.

15. Arreola-Risa C, Speare JOR. Trauma in Mexico. Trauma Q. 1999;14(3):211-20.

16. Mock C, Arreola-Risa C, Quansah R. Strengthening care for injured persons in less developed countries: a case study of Ghana and Mexico. Inj Control Saf Promot. 2003; 10(1-2):45-51.

17. Quansah R. Availability of emergency medical services along major highways. Ghana Med J. 2001;35:8-10.

18. American College of Surgeons Committee on Trauma. Resources for the optimal care of the injured patient: 1999. Chicago: American College of Surgeons; 1999.
19. Maier RV, Rhodes M. Trauma performance improvement. In: Rivara FP, Cummings P, Koepsell T, Grossman D, Maier R, eds. Injury control: a guide to research and program evaluation. New York: Cambridge University Press; 2001. Pp. 236-49.

20. Ali J, Adams R, Butler AK, Chang H, Howard M, Gonsalves D, et al. Trauma outcome improves following the advanced trauma life support program in a developing country. J Trauma. 1993;34:890-8.

21. Chardbunchachai W, Suppachutikul A, Santikarn C. Development of service system for injury patients by utilizing data from the trauma registry. Khon Kaen: Office of Research and Textbook Project, Khon Kaen Hospital; 2002.

22. Driscoll PA, Vincent CA. Organizing an efficient trauma team. Injury. 1992;23:107-10.

23. Sakellariou A, McDonald P, Lane R. The trauma team concept and its implementation in a district general hospital. Ann R Coll Surg Engl. 1995;77:45-52.

24. Ozguc H, Kaya E, Yunuk L, Armagan E, Tokyay R. Outcome of major trauma in a Turkish university hospital: did integrated approach make a difference? Eur J Emerg Med. 2000;7(3):183-8.

Manuscript received 1 April 2005. Revised version accepted for publication 19 August 2005. 
RESUMEN Objetivo. Identificar formas asequibles y sustentables de reforzar los recursos para la atención de heridos en México aplicando las pautas contenidas en Guidelines for Essential Trauma Care [Pautas para el tratamiento básico de los heridos], publicación de

La evaluación de los recursos para el tratamiento de heridos en México a la luz de las pautas publicadas por la Organización Mundial de la Salud, Guidelines for Essential Trauma Care la Organización Mundial de la Salud y de la Sociedad Quirúrgica Internacional que contiene recomendaciones sobre los componentes de la atención de heridos que deben poseer los servicios de salud de distintos niveles en todos los países.

Métodos. Las pautas publicadas (Guidelines) sirvieron de base para llevar a cabo evaluaciones de las necesidades en tres estados mexicanos en 2003 y en 2004. Los estados se escogieron con la idea de que estuviese representada la amplia variedad de condiciones geográficas y económicas del país: Oaxaca (en el sur y de estrato económico inferior), Puebla (en el centro y con un estrato económico mediano) y Nuevo León (en el norte y con un estrato económico más alto). Se evaluaron dieciséis centros entre los cuales había puestos de salud rurales, hospitales pequeños y hospitales grandes. Se hicieron visitas a todos los centros para llevar a cabo la inspección directa de los recursos físicos en cada uno y entrevistar a miembros clave del personal administrativo y clínico.

Resultados. Los recursos humanos y físicos destinados a la atención de heridos eran de calidad satisfactoria en los hospitales, especialmente los más grandes. La encuesta reveló algunas deficiencias, tales como una escasez de succionadores rígidos, oxímetros de pulso y algunos medicamentos usados para tratar heridos. En todos los puestos se observaron dificultades con los equipos básicos de reanimación, a pesar de que algunos recibían un número bastante alto de heridos. En los centros de todos los niveles había margen para mejorar las funciones administrativas a fin de conseguir una atención de calidad que incluyese el mantenimiento de registros de heridos, programas para mejorar la atención de estos pacientes y uniformidad en el adiestramiento del personal durante el desempeño de sus funciones.

Conclusiones. En este estudio se identificaron varias formas baratas de reforzar la atención de pacientes heridos en México. También se subrayó la utilidad de las pautas recomendadas en la obra Guidelines for Essential Trauma Care como modelo estandarizado para evaluar los recursos para el tratamiento de heridos que poseen los países en cualquier parte del mundo.

Palabras clave Servicios médicos de urgencia, calidad de la atención de salud, pautas, México. 